\title{
A TAXIR DATA BANK OF SEED PLANT TYPES AT THE UNIVERSITY OF MICHIGAN HERBARIUM
}

\author{
George F. Estabrook ${ }^{1}$
}

\section{Abstract}

A computerized information management system for use with the curation of seed plant types at the University of Michigan Herbarium is now operative. Its construction, structure, and use are described and illustrated.

In his application for curatorial Grant NSF BMS-72-00071 Professor Rogers McVaugh included provision for the construction of a computerized information management system for the curation of the type specimens at the University of Michigan Herbarium. The construction of such a system is essentially complete for the seed plants (approximately 5500 types), and nearing completion for Mosses, Lichens, and Fungi. A system for Pteridophyte types has been begun. This report describes the Data Bank for seed plant types.

The antities about which information is stored are basionyms, and the type specimens to which they are attached. The basic information in the data bank is of three kinds: What is the name and its taxonomic placement; whomade the name and where was the description published; and who collected the specimen and where was it collected.

The computer system used to make this Data Bank of seed plant types is the *TAXIR system running in the context of the MTS operating system at the University of Michigan Computing Center. Detailed and explicit instructions on how this system can be used has been published by Brill (1978). A description of the theoretical basis of its retrieval algorithm has been published by Estabrook \& Brill (1969).

The descriptions for this data bank are presented below. The FREE field format option was chosen for entering data. In this convention, the specific state of each descriptor, that applies to the basionym being described is entered into a computer readable medium (such as cards).

\section{GENUS}

As it appears in the basionym.

2. SPECIFIC EPITHET

As it appears in the basionym.

3. INFRASPECIFIC EPITHET

As it appears in the basionym, else blank.

4. FAMILY

As recognized by Engler \& Prantl, but slightly modified to reflect widely accepted 5. DIVISION modern concepts.

No longer used since separate banks were made for each major plant group.

6. AUTHORITY

Abbreviations as suggested by the "Author Index" of Kew, else last name followed by all initials each followed by a period. Multiple authors are connected with " $\&$ ".

1 University of Michigan Herbarium, Ann Arbor, MI 48109, U.S.A. 


\section{KIND OF TYPE}

Instances of "in" and "ex" are also included as part of the authority.

The commonly accepted terms: HOLOTYPE, ISOTYPE, SYNTYPE, etc. are used.

8. PLACE OF PUBLICATION

Abbreviations for periodicals as suggested by Botanico-Periodicum-Huntianum 1968.

Book titles in full, except B-P-H conventions are used for commonly abbreviated words.

9. VOLUME

The number of the volume, else blank.

10. PAGE

The number of the page, else blank.

11. FIGURE NUMBER

The very alpha-numeric string of symbols used in the publication to designate the figure, plate, or etc.

12. YEAR OF PUBLICATION

Four numerals as commonly designate a year.

13. PLACE OF PUBLICATION REMARKS

Up to 99 alpha-numeric symbols.

14. HERBARIUM

All specimens reside at $\mathrm{MICH}$.

15. HERBARIUM NUMBER

Blank, as MICH does not use one.

16. COUNTRY

17. STATE

Country of collection, English spelling of modern name.

State, province, or major political subdivision.

18. COUNTY

County, municipality, or other minor political subdivision.

19. LOCALITY

Any additional locality data, in less than a hundred characters.

20. FIRST COLLECTOR

Last name, followed by initials, e.g., COWAN R.S.

21. SECOND COLLECTOR

If only one collector then blank, else if only two collectors, then name of second collector, as in 20 , else the characters "et al.".

22. OTHER COLLECTORS

Blank. Two collectors were enough.

23. COLLECTION NUMBER

The numerical part of the collection number. This is the entire collection number in most cases.

24. COLLECTION NUMBER PREFIX

If a nonnumerical symbol appears near the beginning of the collection "number", then this is the string of symbols from the beginning of the "number" through the last such nonnumerical symbol, else blank.

25. COLLECTION NUMBER POSTFIX

Same as 24 except encodes case in which a nonnumerical symbol appears near the end of the collection "number".

26. OTHER NUMBER

Any other "number", if present.

27. DAY OF COLLECTION

An integer 1 through 31 to designate day number in date of collection.

28. MONTH OF COLLECTION

First three letters of the month name in date of collection.

29. YEAR OF COLLECTION

Like 12. 


\section{COLLECTION REMARKS}

Like 13.

31. MISC. REMARKS

Like 13.

32. RANK

To designate the rank of the basionym use one of the following: SP, SSP, VAR, SUBVAR, FMA, SUBFMA

33. DATE RANGE

If date of collection is given as a range then this is "yes" and 27, 28, and 29 are the earliest date given, else blank.

34. DIACRITICAL MARKS OMITTE D

If foreign spellings require diacritical marks then this is the names of the descriptors from whose states such marks have been omitted, else blank.

\section{TYPE OF MINOR GEOGRAPHICAL SUBDIVISION}

The kind of subdivision, e.g, County, District, Comisaria, named in 18.

36. LOCATION OF HOLOTYPE

Herbarium acronym.

These descriptor states can be of variable length, and are separated by commas. When data prepared in this way are entered into a ${ }^{*}$ TAXIR system, the order in which the descriptor's states will be presented is specified so that the information in each such "free field" can be associated with the proper descriptor. The order in which data were usually presented to *TAXIR is $1,2,3,32,7,4,5,6,8,9,10,11,12$, $14,15,36,20$ thru 29, 33, 30, 16, 17, 18, 35, 13, 19, 34. This order made data preparation easier by grouping related information together.

Among the states of a descriptor, each distinct string of symbols is considered a unique descriptor state (except that instances of more than one consecutive blank are reduced to only one blank). Thus, it is important to establish standard conventional ways to present information. For example, in the descriptor, Authority, McVaugh $\mathrm{R}$ and McVaugh R. would be considered distinct authorities. Table 1 also provides descriptions of conventions that have been used to present data.

When the basionyms have all been described to *TAXIR and the Data Bank is complete, ${ }^{*}$ TAXIR can provide, for each descriptor, lists of all the descriptor states that have occurred in the data. Such lists are called the control vocabulary because these terms can be used to control for which basionyms information will be printed. The complete control vocabulary for the data bank of flowering plant types is enormous, but small portions of it are presented below, in order to illustrate the concept.

TAXIR OUTPUT: $\quad$ DEC $17,1977 \quad$ PAGE 1 $\mathrm{V}^{*}$

1. GENUS

\begin{tabular}{|c|c|}
\hline \multicolumn{2}{|c|}{ TYPE: NAME $\quad$ NO. OF STATES: 1453} \\
\hline \\
\hline \multicolumn{2}{|c|}{$\begin{array}{l}\text { AMBIG: CODE LARGEST CODE NO. } \\
\text { CODE NAME }\end{array}$} \\
\hline \multicolumn{2}{|c|}{$896 \quad$ ABIES } \\
\hline & ABOLBODA \\
\hline & ABORTOPETALUM \\
\hline & ABUTA \\
\hline & ABUTILON \\
\hline \multirow{2}{*}{$\begin{array}{l}647 \\
667\end{array}$} & ACACIA \\
\hline & ACACIELLA \\
\hline \multirow{2}{*}{$\begin{array}{r}1514 \\
320\end{array}$} & ACALYPHA \\
\hline & ACANTHOTHAMNUS \\
\hline \multirow{2}{*}{$\begin{array}{r}948 \\
1\end{array}$} & $\mathrm{ACCA}$ \\
\hline & ACER \\
\hline 2 & ACERATES \\
\hline
\end{tabular}


TAXIR OUTPUT: $\quad$ DEC 17, 1977 PAGE 59

2. SPECIFIC EPITHET (continued)

CODE NAME

941 MCVAUGHIANA

16 MCVAUGHII

1535 MEDIA

830 MEDULLOSA

1617 MEGACARPA

2816 MEGACARPUM

571 MEGACEPHALA

618 MEGACEPHALON

908 MEGALANTHA

1347 MEGALANTHUS

4. FAMILY

TYPE: NAME NO. OF STATES: 193 PRINT FIELD SIZE: 16 AMBIG: CODE LARGEST CODE NO.: 322

CODE NAME

16 ACANTHACEAE

1 ACERACEAE

41 ACTINIDIACEAE

8 ALISMATACE AE

12 AMARANTHACEAE

7 AMARYLLIDACEAE

32 ANACAR DIACE AE

14 ANONACEAE

11 APOCYNACEAE

39 AQUIFOLIACEAE

TAXIR OUTPUT: $\quad$ DEC 17,1977 PAGE 102

6. A UTHORITY (continued)

CODE NAME

$228 \quad$ BUSH

672 C. DC.

915 C. \& R.

1053 CALDERON G.

1054 CAMBESSEDES

129 CAMP

876 CARLSON

763 CARTER IN BENSON \& CARTER

632 CASE F.W.

699 CHASE

735 CHING

1112 CHING EX TARDIEU \& CHRISTENSEN C.

270 CHODAT

502 CHODAT \& HASSLER

658 CHODAT EX RUSBY

7. KIND OF TYPE

TYPE: ORDER NO. OF STATES: 7 PRINT FIELD SIZE: 12

CODE NAME

1 HOLOTYPE

2 ISOTYPE

3 SYNTYPE

4 ISOSYNTYPE

5 LECTOTYPE

6 ISOLECTOTYPE

7 NEOTYPE

8 MEROTYPE 
TAXIR OUTPUT: $\quad$ DEC 17, 1977 PAGE 120

11. FIGURE NUMBER (continued)

CODE NAME

$27 \quad 60$

12. YEAR OF PUBLICATION

TYPE: FROM-TO NO. OF STATES: 248

FROM 1753 TO 2000 BY 1

13. PLACE OF PUBLICATION REMARKS

TYPE: NAME NO. OF STATES: 464 PRINT FIELD SIZE: 91

AMBIG: CODE LARGEST CODE NO.: 464

CODE NAME

384 \#MISPRINTED IN MADRONO AS 10462

$220 \quad \# 2$

215 \#2449 ALSO CITED. REMOVED TO

366 \#CITED AS PISTILLATE TYPE IN

ORIG. DESCR.

23. COLLECTION NUMBER

TYPE: FROM-TO NO. OF STATES: 200000 PRINT FIELD SIZE: 6

FROM 1 to $200000 \mathrm{BY} 1$

24. COLLECTION NUMBER PREFIX

TYPE: NAME NO. OF STATES: 15 PRINT FIELD SIZE: 4

AMBIG: CODE LARGEST CODE NO.: 15

CODE NAME

$15-S$

3 A

13 A.

6 C-

$1 \quad \mathrm{E}$

$7 \quad$ E-

$2 \quad \mathrm{H}$

$8 \quad$ II

27. DAY OF COLLECTION

TYPE: FROM-TO NO. OF STATES: 31 PRINT FIELD SIZE: 2

FROM 1 TO 31 BY 1

28. MONTH OF COLLECTION

TYPE: ORDER NO. OF STATES: 12 PRINT FIELD SIZE: 3

CODE NAME

1 JAN

2 FEB

3 MAR

$4 \quad$ APR

The *TAXIR system can be given instructions to print out portions of the information that is stored in the data bank of seed plants. There are two aspects in which this desired portion must be specified: for which basionyms is information desired?; and, for which descriptors is information desired?. Thus, a *TAXIR query has two parts. One part is a logical combination of properties of basionyms (structured as a Boolean expression with descriptor states as operands). This part specifies which basionyms are of interest. One simple form of query asks how many basionyms satisfy the specified condition. An example below illustrates this.

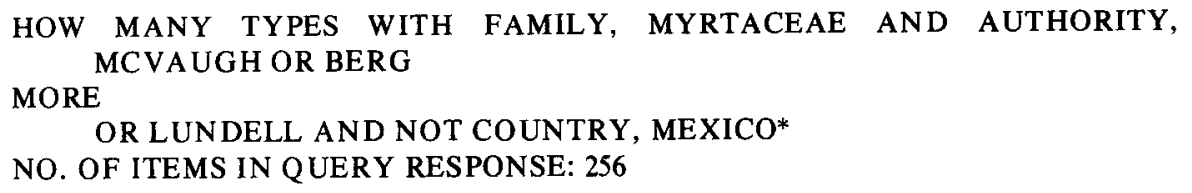


Information about the basionyms that satisfy a specified condition can also be requested by listing the descriptors whose states are to be printed. This is illustrated in the example below.

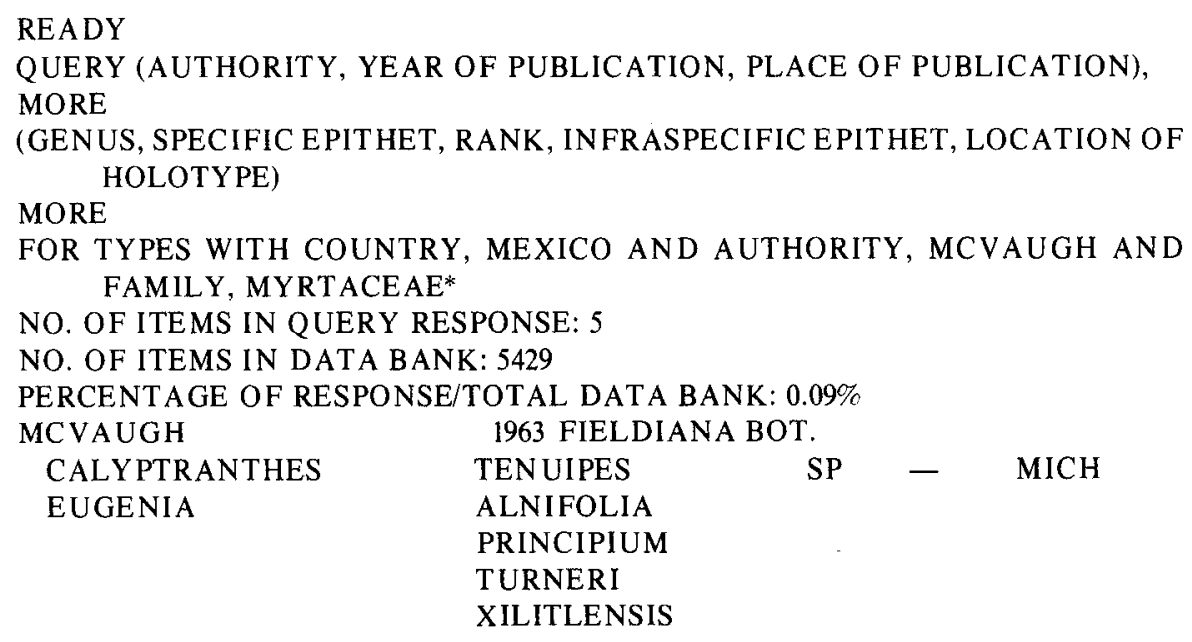

For immediate reference, *TAXIR has also printed out a complete citation of each basionym. These are arranged alphabetically by Family; within Family alphabetically by Genus; within Genus alphabetically by Species; within Species alphabetically by Infraspecific epithet. A portion of this listing is given in the example below.

\section{CAMPANULACEAE}

CENTROPOGON MINIMUS MCVAUGH BRITTONIA 6: 467. 1949 ISOTYPE

EWAN J. $1569923^{-}$MAY 1944 HOLOTYPE AT NA COLOMBIA ANTIOQUIA DEPARTMENT

PARAMO DE SONSON ABOVE SONSON; ELEV. 2743 M

$\begin{array}{lllll}\text { CENTROPOGON MONAGENSIS MCVAUGH } & \text { BRITTONIA } & 3: 472 . & 1940\end{array}$ ISOTYPE

STEYERMARK J. A. 618625 APR 1945 HOLOTYPE AT F VENEZUELA MONAGAS

CERRO NEGRO ABOVE LA SABANA DE LAS PIEDRAS NW OF CARIPE ALT. $1500 \mathrm{M}$

CENTROPOGON OAXACANUS VAR BERTERIOIDES WIMMER

E. PFLANZENREICH IV 276: 840, 1968 HOLOTYPE

HOLM RICHARD W. \& ILTIS HUGH H. 120 25 JUN 1949 COSTA RICA CARTAGO

SMALL VALLEY NEAR SANTA CRUZ; SOUTH SLOPE OF VOLCAN TURRIALBA; ELEV. $1430 \mathrm{M}$

CENTROPOGON TALAMANCENSIS WILBUR BRITTONIA 21:255. 1970 ISOTYPE

WILBUR R. L. \& STONE $\quad$ D. E. 1005327 JAN 1968 HOLOTYPE AT DUKE COSTA RICA CARTAGO

ALONG THE CARRETERA INTERAMERICANA AT ABOUT $97 \mathrm{KM}$; VIC. OF RES-

TAURANTE LA GEORGINA; ELEV. $3100 \mathrm{M}$ 
CENTROPOGON UNCIALIS MCVAUGH J. WASH. ACAD. SCI. 39: 159. 1949 HOLOTYPE

GARCIA-BARRIGA H. 1074422 FEB 1942 COLOMBIA CUNDINAMARCA ENTRE PACHO Y RIO NEGRO; ELEV. 1000 A $1200 \mathrm{M}$

DATE RANGE 22-26 FEB 1942

Many ways to improve the design of a Type data bank such as this have already become apparent. Information concerning Volume, page, and figure number should all be placed in one descriptor. Detailed locality data probably should not be included, but left to reside on the label only. All the collectors' names should be put in one descriptor, just as they would appear in exsiccatae citations. Ideally, only collectors in whose number series occurs the collection number should be included. Remarks should be held to a minimum, and these in one descriptor only.

The extent and manner of use of this data bank remains to be seen. The opportunity to try and to test this modern curatorial tool, however, has been made possible by the support and help of Rogers Mc Vaugh.

\section{Literature Cited}

Brill, R. C. 1978. The Taxir Primer 3rd ed. University of Michigan Computing Center, Ann Arbor, Mi. 179 pp.

Estabrook, G. F. and R. C. Brill 1969. The Theory of the Taxir Accessioner. J. Math. Bioscience 5: 327-340. 